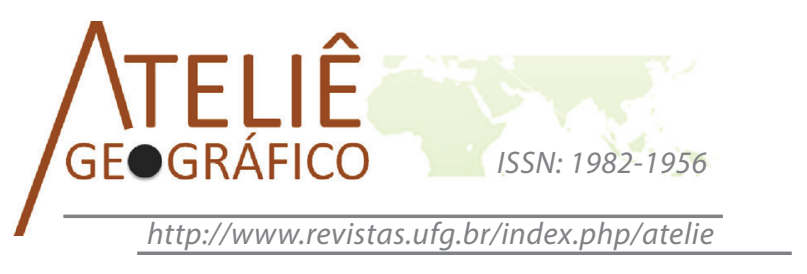

\title{
Liberdade sob duas rodas: as espacialidades vividas pelos praticantes de Mototurismo
}

\author{
Freedom under two wheels: the spacialities lived by the \\ practitioners Mototourism
}

\section{Liberté sous deux roues: les espacialités vécus par les praticiens de Mototourisme}

\author{
Raquel Lage Tuma \\ Instituto Federal de Educação, Ciência e Tecnologia de Goiás \\ tuma.raquel@gmail.com \\ Maria Elisabeth Alves Mesquita \\ Faculdade Alfredo Nasser \\ geoelisabeth@gmail.com \\ Carlos Eduardo Santos Maia \\ Universidade Federal de Juiz de Fora \\ carlmaia@uol.com.br
}

\begin{abstract}
Resumo
$\mathrm{O}$ artigo tem por objetivo apresentar o mototurismo por meio de uma análise do deslocamento espacial daqueles que buscam por liberdade, como uma opção de lazer e de uma escolha de vida que tem como principal motivação a liberdade. Conceituação e aplicação do termo liberdade fazem parte desta pesquisa, assim como as teorias: da viagem, de conformismo, de nomadismo e as motivacionais. Como o motociclista praticante de mototurismo tem viajado para eventos, é discutido os tipos de eventos motociclísticos existentes unidos aos estudos de turismo de eventos. Como procedimento metodológico foram realizadas entrevistas e visita a campo nos dois maiores eventos motociclísticos do Estado de Goiás, com foco nos praticantes dessa modalidade crescente no Brasil.

Palavras-chave: Mototurismo, Liberdade, Turismo de eventos.
\end{abstract}




\begin{abstract}
The article aims to present the mototour through an analysis of the spatial displacement of those who seek for freedom, as a leisure option and a choice of life whose main motivation freedom. Conceptualization and application of the term freedom are part of this research, as well as theories: the journey of conformity, of nomadism and motivational. As the practitioner biker mototour has traveled to events is discussed the types of motorcycle attached event to tourism studies. As a methodological procedure were carried out interviews and field visits to the two largest motorcycle events in the state of Goiás, focusing on practitioners of this growing sport in Brazil.
\end{abstract}

Key words: Mototour, Freedom, Events of the Tourism.

\begin{abstract}
Résumé
L'article vise à présenter le mototourisme par une analyse du déplacement spatial de ceux qui cherchent la liberté, comme une option de loisirs et un choix de vie dont la liberté est la principale motivation. La conceptualisation et l'application d'expression liberté font partie de cette recherche, ainsi que les théories: du voyage de conformité, de nomadisme et de motivation. Comme le motard praticien de mototourisme a voyagé à des événements, est discutée types d'événements de moto existant attaché à des études de tourisme d'événements. Comme prodédure méthodologique ont mené des entretiens et des visites dans les deux plus grands événements de moto dans l'État de Goiás, se concentrant sur les praticiens cette modalité croissant au Brésil.
\end{abstract}

Mots-clés: Mototourisme, Liberté, Tourisme d'evenements.

\title{
Introdução
}

Os sorrisos, os braços abertos, a ausência do capacete, o vento no rosto bagunçando os cabelos, o rosto e as mãos vulneráveis às condições do tempo, a poeira, a estrada, a confiança no parceiro pilotando, a moto e a paisagem ao redor são elementos que tentam ilustrar essa experiência que é o viajar de moto e o discurso de liberdade intrínseco nessa ação. Essa imagem foi extraída do Filme: Diário de Motocicleta (2004), que narra a trajetória feita em 1952, pelos viajantes: Ernesto Guevara, o conhecido Che Guevara, e o amigo Alberto Granado ao realizarem uma clássica viagem de moto pela América do Sul, partindo da Argentina, passando por Chile, Peru, Colômbia e chegando até Venezuela.

Algumas indagações permeiam esse ato de viajar e faz essa imagem abrir as discussões. A principal delas está no motivo de terem viajado especificamente de moto ressaltam-se ao mesmo tempo algumas características desses viajantes, a fim de explicitar os sujeitos motociclistas, eram eles: jovens, homens, estudantes de medicina, solteiros e de classe média. A partir desse perfil é possível começar a compreender como o termo liberdade será utilizado nessa discussão.

Assim, em questões de procedimentos metodológicos, buscou-se embasamento na pesquisa documental e bibliográfica de caráter exploratório, com aplicação de 
entrevistas a motociclistas e não-motociclistas de Moto Clubes. Para tanto, foi preciso ir até eles nos eventos motociclísticos, e os escolhidos foram os dois maiores do Estado de Goiás, $18^{\circ}$ Aniversário dos Anjos da Liberdade Moto Clube na Cidade de Goiás e o $11^{\text {a }}$ Parada Obrigatória na Cidade de Morrinhos. No texto a seguir, procurou-se discutir a liberdade como uma motivação pela qual uma pessoa escolhe a motocicleta como de um estilo de vida, consequentemente os aspectos nos quais estes estão envolvidos no que tange o mototurismo e do turismo de eventos.

\section{Viajar de moto é estar livre!}

A afirmação que intitula este tópico e a imagem (Figura 01) são propositais e trazem as vozes dos (as) motociclistas pesquisados (as); visto que, ter uma moto e fazer a escolha de viajar especificamente nesse tipo de veículo é para eles uma busca de liberdade (Figura 01). Ser livre e buscar a liberdade através de um objeto, a moto, é o que vai interpor a discussão a partir deste momento. "Moto" é a forma coloquial utilizada no Brasil para denominar a motocicleta, esse veículo de duas rodas carregado de significados.

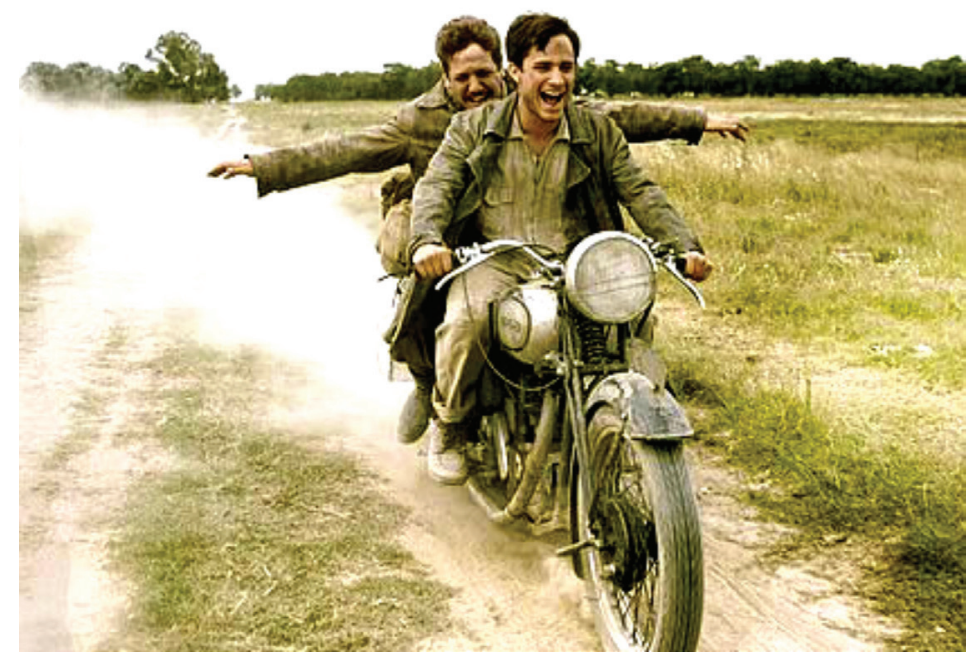

Figura 01: Viajar de moto é estar livre!

Fonte: Diários de Motocicleta (2004)

Para Grimal (1990) a palavra liberdade é uma das mais obscuras que existem e ao mesmo tempo uma das mais comovedoras e perigosas de que se tem notícia. Esse termo é conhecido como fonte de espontaneidade e de vida, é a própria manifestação da vida. "E ter um tempo para seu bel-prazer, como o lazer é uma forma de liberdade, a liberdade é uma noção (ou um sonho) multiforme" (GRIMAL, 1990, p. 10). Vive-se atualmente em uma sociedade de fato capitalista, onde tudo é mercadoria, e a mercadoria-dinheiro 
se torna condição para satisfação de necessidades, a própria liberdade é severamente restrita e, ser livre vai depender da capacidade financeira das pessoas. Sendo assim, é possível vê-la agregada a um objeto, a motocicleta e sua capacidade de mover, afinal o deslocamento demonstra estar livre, o desprende das garras das pequenas circulações rotineiras. Isso seria o lazer, essa forma de liberdade proposta pelo autor, com um sentido alusivo.

A experiência de se sentir liberto não significa necessariamente que alguém seja livre, é uma sensação momentânea. A consciência da liberdade ao viajar de moto, autoriza afirmar a existência de uma sensação temporária. "A consciência psicológica da liberdade é uma experiência direta do sentimento de ser livre" (MENDONÇA, 1977, p. 59). Desta maneira, o que é tido como liberdade para esses motociclistas viajantes, pode não ser o mesmo para outros, se torna experiências pessoais, subjetividades individuais.

A liberdade que se observou entre os sujeitos pesquisados equipara-se também a que foi proposta por Sartre (1999), sendo própria do sujeito e sua consciência autônoma em escolher o que é para si estar livre.

Certamente, eu não poderia descrever uma liberdade que fosse comum ao outro e a mim; não poderia, pois, considerar uma essência de liberdade. Ao contrário, a liberdade é fundamento de todas as essências, posto que o homem desvela as essências intra - mundanas ao transcender o mundo rumo às suas possibilidades próprias. (SARTRE, 1999, p. 542).

Estar solto passa pela própria condição de ser homem, a partir do que lhe é apresentado no decorrer da vida e, na medida em que se tem acesso às informações, esse homem é capaz de fazer suas escolhas. No contexto sartreano toda ação, escolha, objetivo de vida são produtos de uma liberdade humana, de fato restrita, mas não negada. Nesse sentido, ser livre deixa de ser uma conquista do indivíduo para ser uma condição da própria existência humana, afirmação que é base do existencialismo francês. "O homem é tão-somente, não apenas como ele se concebe, mas também como ele se quer; como ele se concebe após a existência, como ele se quer após o impulso para a existência. $\mathrm{O}$ homem nada mais é do que aquilo que ele faz de si mesmo.” (SARTRE, 1987, p. 06).

Foi apresentado ao homem "o carro e a moto" e ele escolheu a motocicleta, para que ele mesmo pilote ${ }^{2}$ em suas viagens de lazer. Uma escolha restrita, o de deixar de viajar de automóvel, com todo o seu aparato de segurança e despreocupação com as condições climáticas e querer viajar de motocicleta, veículo que se é atribuído o conceito de insegurança e elevada periculosidade, devido à alta exposição do corpo. Ressalta-se que $98 \%$ dos entrevistados possuem os dois tipos de veículos.

Se esses fins já estão posicionados, o que falta decidir a cada instante é a maneira de como irei conduzir-me a relação a eles, ou, dito de outro modo, a atitude que vou tomar. Serei voluntário ou apaixonado? Quem pode decidir senão eu? Com

1. Esta pesquisa possui como foco a relação de escolher entre o carro e a moto, sendo esses os dois veículos mais utilizados pelo homem em seus deslocamentos.

2. O verbo pilotar é o mais utilizado entre os pesquisados, sendo assim, foi decidido usar o mesmo que eles. 
efeito, se admitíssemos que as circunstâncias decidissem por mim, estaríamos com isso suprimindo toda liberdade. (SARTRE, 1999, p. 549).

Os princípios norteadores das escolhas é o que fazem o homem ser livre. A problemática está na "paixão" em viajar de moto, escolha que poucos fazem. Viana (2013) enxerga essa escolha como a autonomia relativa do indivíduo e a capacidade de locomoção depende desse grau de autonomia. Só é possível viajar se tiver algumas condições pertinentes para tal fato, como: tempo livre, condição física, financeira e técnica material (a motocicleta). A imagem a seguir unida à frase emblemática ressalta essa autonomia do ser liberto, esse tipo de iconografia está presente em sites, blogs, comunidades virtuais e redes sociais sobre o motociclismo de viagem (Figura 02).

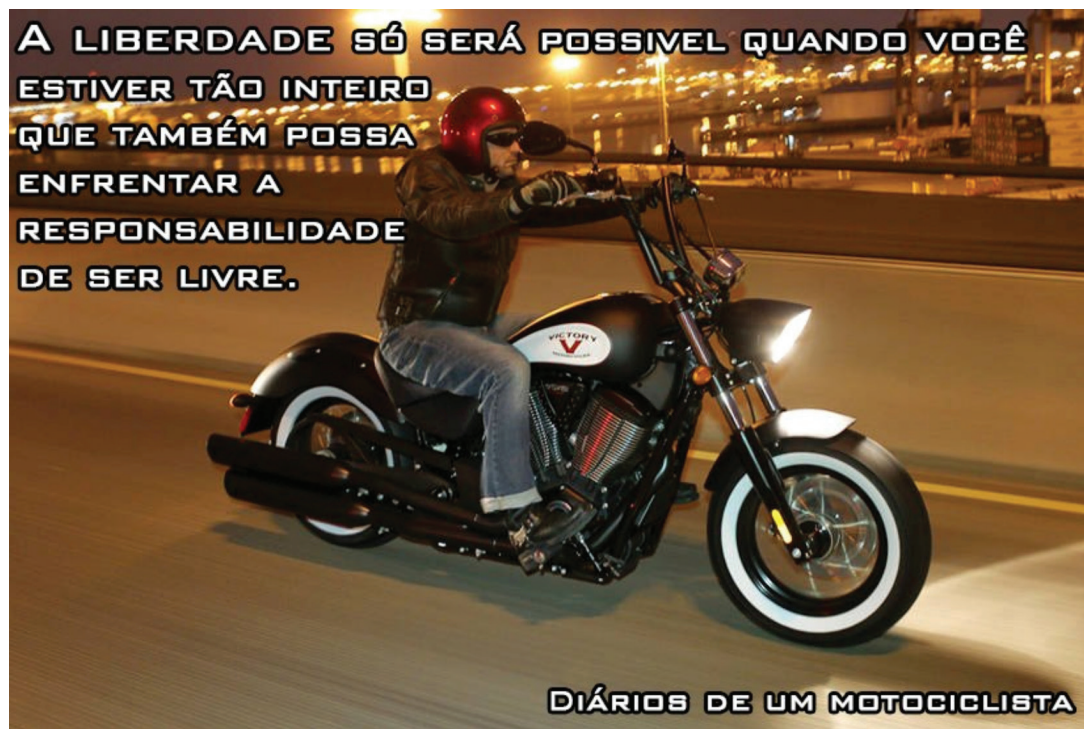

Figura 02: Motociclismo e Liberdade Fonte: Diários de um motociclista (2014)

Os termos: "paixão por moto" e "paixão por duas rodas" estiveram presente em toda a pesquisa, tanto no discurso dos entrevistados, quanto nas suas postagens em redes sociais: "Viajar de moto é uma paixão que passou de pai para filho." (Entrevistado 01). "Ser apaixonado por motos é coisa que vem de sangue." (Entrevistado 02).

Essa "paixão" coexiste como uma vontade subjetiva de possuir um objeto e utilizá-lo para deslocamento com maior relação espaço temporal, como sair em viagem e ter as sensações desejadas. É o que a filosofia existencialista sartreana chama de escolha, fazer uma escolha por paixão e conseguir atingir o determinado fim, a liberdade. "Não poderia, portanto, limitar-se aos atos voluntários. Mas as volições são, ao contrário, tal como as paixões, certas atitudes subjetivas através das quais procuramos atingir fins 
posicionados pela liberdade original." (SARTRE, 1999, p. 549). O termo volição trago pelo autor vem do latim, volitione, e pode ser definido da seguinte forma:

[...] um processo cognitivo pelo qual um dos indivíduos se decide a praticar uma ação em particular. É definida como uma um esforço deliberado e é uma das principais funções psicológicas humanas (sendo as outras: afeto, motivação e cognição). Processos volitivos podem ser aplicados conscientemente e podem ser automatizados como hábitos no decorrer do tempo, sendo eles certos ou errados, neste momento de escolha não houve esse juízo de valor. (MARTINS, 2014, p.01).

Esse processo volitivo nesta pesquisa analisado, viajar de moto, é muito questionado. "Nossa! Eu acho uma bobeira, e ainda têm uns que viajam em época de chuva, e o pior, a maioria deles tem carro em casa." (Entrevistado 03). Viajar de moto ainda é tido como algo perigoso e sem conforto no olhar do de fora. Ressalta-se que esse é um olhar generalizado, afora os motociclistas, poucos concordam com o feito, o viajar de moto. Mendonça (1977) argumenta que ser livre é próprio de ser do homem e está vinculada à sua capacidade de desenvolvimento e aperfeiçoamento pessoal. A ação libertadora manifestada nas suas relações externas só é legitima na medida em que se torna a expressão da libertação individual e subjetiva de cada um.

Nessa busca pessoal proporcionada pela viagem de moto, há um fato que requer muita atenção, o de exaltarem o caminho, a estrada, o percurso e não o destino final. É como se a liberdade de escolher viajar de moto fosse mais importante do que o viajar em si e o retornar para casa. Sartre (1999) salienta que o êxito final não influi na liberdade e sim a autonomia de escolha.

A maioria dos turistas tidos como comuns saem de suas residências e deslocam até um ponto fixo para praticar o lazer, não se importando muito com a trajetória, ocorrência da pesquisa Sondagem do Consumidor em relação à intenção de viagem nos próximos seis meses, realizada em dezembro de 2014, divulgada pelo Ministério do Turismo. O estudo revelou que $48,7 \%$ da população brasileira têm intenção de usar o avião como meio de transporte, contra $34,6 \%$ com preferência pela utilização de automóvel e 14\% ônibus (BRASIL, 2015). Vale atentar que na pesquisa não é feito o levantamento específico de motocicleta. Porém, em pesquisa anterior, realizada pelo mesmo órgão público em 2011, a fim de fazer a caracterização das viagens domésticas, demonstrou que nas viagens a lazer $47,7 \%$ das pessoas preferiam fazer de carro, $15,7 \%$ de avião e a moto surge com $0,9 \%$ (MINISTÉRIO DO TURISMO, 2012). Com os dados acima, constata-se uma queda no interesse em viagens utilizando-se das rodovias, onde uma minoria se importa com estrada, com a paisagem e escolhe viajar de automóvel ou de motocicleta, dando ênfase ao caminho percorrido, e nisso está o lazer. Em 90\% dos entrevistados percebeu-se a importância dada para estrada, para os espaços percorridos, para as paisagens visualizadas, sentidas e vividas; chegando a afirmar que fazem parte dessa paisagem, como demonstra a imagem também acoplada a uma frase chamativa (Figura 03). 


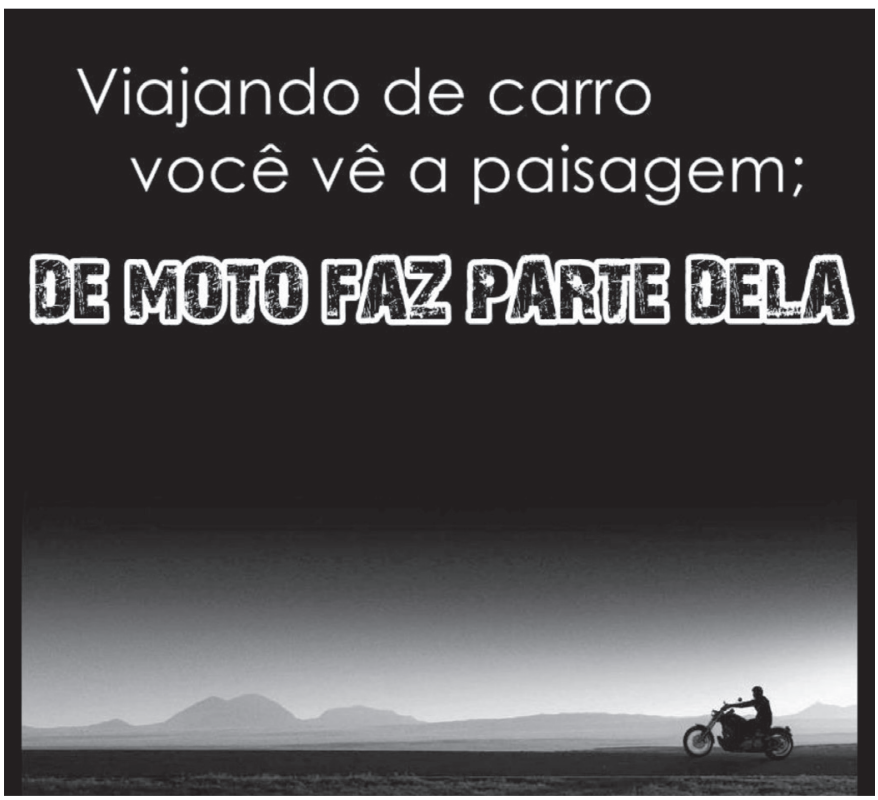

Figura 03: Motociclismo e Paisagem

Fonte: Diários de um motociclista (2014)

É como se os contornos do corpo humano e da motocicleta dessem continuidade aos desenhos do relevo e cada quilômetro percorrido uma nova paisagem composta. Outro fato é a visão lateral que se tem com uma motocicleta, o poder mover a cabeça e não encontrar armações de ferro por todos os lados que não permitem enxergar uma paisagem por inteiro, o que ocorre em um automóvel. O que Onfray (2009) descreve da seguinte forma:

A viagem pode oferecer uma oportunidade para desenvolver os cinco sentidos: sentir e escutar mais profundamente, olhar e ver com mais intensidade, degustar e tocar com mais atenção - o corpo desassossegado, tenso e aberto a novas experiências, registra mais informações do que habitualmente. (ONFRAY, 2009, p. 52).

Com o intuito de melhor compreender esses viajantes de moto, por essa odisseia da liberdade pessoal, com esse poder de persuasão aumentado, ora solitários, ora em grupo (como o caso dos Moto Clubes) e suas relações com essa paisagem da estrada, é que se entra nesse item a seguir.

\section{Motivações para "pegar a estrada"}

Ao investigar as motivações que levam o sujeito a viajar, viu-se que a ação de viajar não é de todo o ser humano e não depende de condição social, em especial a questão 
financeira e o tempo livre. Wenge (2014) aponta que nem todos os homens tendem a ter impulsos de deslocamentos para o lazer, existem pessoas que realmente não gostam de viajar. Este fato se confirma na pesquisa realizada pelo Ministério do Turismo, quando perguntado sobre a razão para não viajar, a qual 12,9\% dos entrevistados responderam por não gostar de viajar ou não ter o hábito (MINISTÉRIO DO TURISMO, 2012). Vincula-se isso à Teoria do Conformismo: conformados, acomodados e felizes com o não viajar. Esse conformismo vê na viagem uma atitude de migração e nomadismo, que não encaixam em suas rotinas de lazer, e atribuem às viagens turísticas como dever para determinada classe social, um status, uma ostentação. Tem-se nessa teoria uma explicação aplausível para o julgamento negativo de pessoas contra o viajar, contendo mais ênfase negativa no viajar de moto.

Conformidad en este contexto e su comportamiento o una actitud que responde a determinadas expectativas de reconocimiento social [...] Migración y nomadismo, así como el ímpetu por descubrir, son de acuerdo a esta teoría impulsos elementares del hombre que se manifestan mediante el viaje. Componentes sócio-económicos no son apenas considerados. (WENGE, 2014, p. 89).

Com esse contexto nota-se que esses deslocamentos para o lazer é algo complexo e subjetivo de cada ser, tanto a escolha do viajar quanto a de ir exclusivamente de moto. Para tentar sanar essa complexidade os conceitos de Motivação (BERGAMINI,1990), de Teoria da Viagem (ONFRAY, 2009) e de Nomadismo (MAFFESOLI, 1997) irão iniciar essa discussão.

Bergamini (1990) diz que existem dois vieses para compreender o fenômeno da motivação humana para viajar: um é a força que conduz o comportamento motivado, nesse caso a busca da liberdade em viajar de moto, está fora da pessoa, nasce de fatores intrínsecos que são de certa forma: soberanos e alheios a sua vontade; e o outro é que as ações humanas são espontâneas e gratuitas, uma vez que tem suas origens nas impulsões interiores, o próprio ser humano traz em si seu potencial e a fonte de origem do seu comportamento motivacional. Portanto, o segundo viés é o que melhor tenta resolver indagação do impulso de viajar de moto, com a espontaneidade vista também em Sartre (1987) supracitado; visto que, se o indivíduo fosse realmente motivado de fora para dentro muitas forças seriam capazes de influenciá-lo e dominá-lo, e se tornaria um sujeito feliz, mas não é isso que acontece.

A motivação é pessoal, nasce nas necessidades intrínsecas e que encontra sua fonte de energia nas emoções. A necessidade não satisfeita é a sede e nela reside a motivação e todo esse processo se origina nas carências internas que predispõem o indivíduo a um comportamento de busca, que tem como finalidade satisfazê-las. Trata-se de um ciclo interno, só pode ser entendido como algo interior a ela (BERGAMINI, 1990, p.30).

"Não dá para explicar a emoção que é planejar o ano todo, uma viagem, e aí chega o dia. E cair na estrada, é bom demais." (Entrevistado 04). Essa satisfação da carência resolvida nesse "cair na estrada" e essa busca ousada por uma motivação 
pessoal, o ser livre, é vista pelo autor como uma forma do homem deixar de ser passivo e acomodado, o viajar de moto o predispôs a uma iniciativa ousada rumo à sua autorealização. Ressalta-se que nem todos os indivíduos possuem acesso a aquilo que irá lhe trazer motivação e proporcionar a sensação de liberdade por muitos buscados; e que também existem pessoas que isso não os farão falta no decorrer da vida social e nas escolhas pessoais.

Onfray (2009) crê que existem dois tipos de indivíduos no mundo, os nômades e os sedentários: "os primeiros gostam da estrada, longa e interminável, sinuosa e ziguezagueante, os segundos adoram o solo, sombrio e profundo, úmido e misterioso." (ONFRAY,2009, p.10). Dessa forma o autor tenta teorizar a viagem, explicar o motivo das pessoas viajarem, se deslocarem e, ao mesmo tempo, responde o porquê de outros não fazerem tal ato. Chega-se ao ponto de concluir que esses dois indivíduos são extremamente importantes para cada sociedade em que está inserido, tanto o cidadão fluxo como o fixo, e utiliza para compreender essa relação intrínseca o exemplo do pastor e do camponês:

Estes dois mundos apoiam-se e opõem-se. Os pastores percorrem vastas extensões, pastam os seus rebanhos sem preocupações políticas ou sociais a organização comunitária tribal pressupõe algumas regras, sem dúvida, mas todas muito simples: os camponeses instalam-se, constroem, erguem, edificam aldeias, cidades, inventam a sociedade, a política, o Estado, portanto, a Lei [...] (ONFRAY, 2009, p.11).

Com o nascimento do capitalismo ocorre a recusa a essa ordem social, o que é nômade inquieta ao poder, é tido como o incontrolável, o livre, o impossível de perseguir, difícil de fixar e, consequentemente, de ser convocado para votar. Mesmo sendo importantes esses dois indivíduos para a sociedade, os nômades sempre serão "mal vistos", devido a essa liberdade. Podem-se citar como exemplo os caminhoneiros, os marinheiros, os pescadores, os pilotos, os comissários de bordo e os andarilhos. Mesmo que modernize as técnicas de locomoção de mercadorias essas pessoas são "apaixonadas" por sua liberdade. "Tire um caminhoneiro da estrada e terá um homem doente em pouco tempo.” (BRASIL, 2014).

Dentro desse ensejo estão também os motociclistas e sua paixão em viajar de motocicleta. Não é satisfatório para eles ter uma motocicleta e pilotar na cidade, é preciso estar na estrada, ver uma paisagem que para eles fazem todo o sentido: qualquer paisagem do mundo cortada por uma estrada, essa é a paisagem perfeita (Figura 04).

As motivações para "pegar a estrada" de Onfray (2009) estão nos indivíduos que se descobrem nômades em algum momento da vida e optam por fazer essa escolha com viagens curtas, deslocamentos de finais de semanas, viagens longas, ou possuem a viagem como sua profissão, ou dão volta ao mundo, ou ainda se tornam andarilhos e mendigos/moradores de rua. Esses últimos sem endereço, sem nenhum ponto fixo que os prendem, e para o autor eles sempre existirão em todas as sociedades, pois obedecem a impulsos intrínsecos de seu ser nômade, gostam dessa liberdade. 


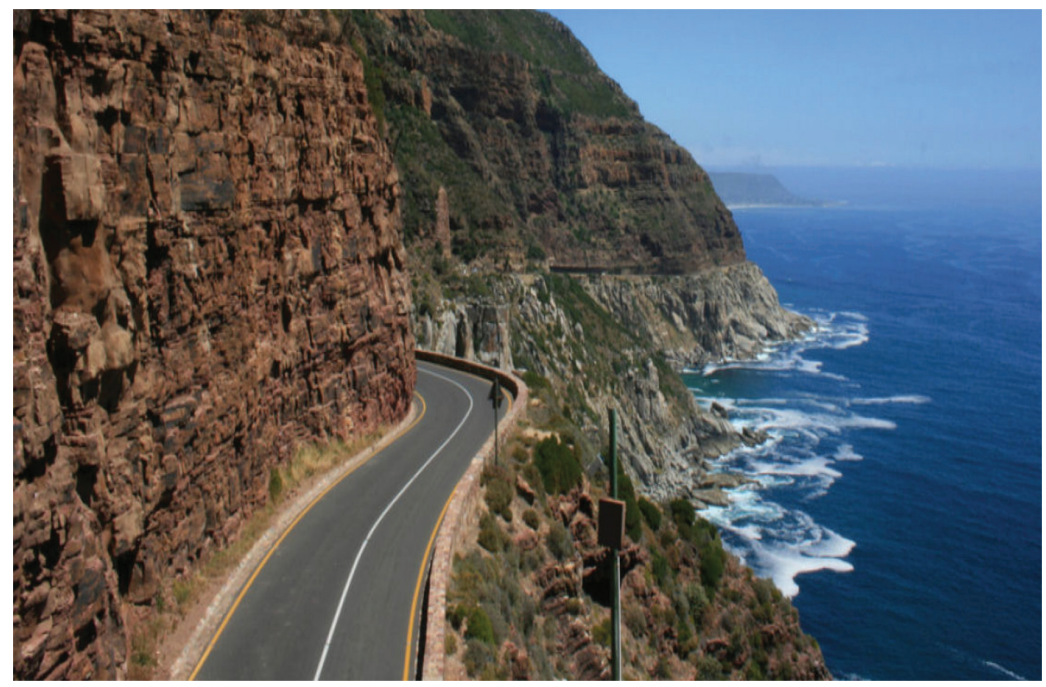

Figura 04: Peak Drive Chapman, Cidade do Cabo, África do Sul Fonte: Brandão (2015)

Maffesoli (2001) insere esse nomadismo ao princípio de errância. Esse seria uma forma de ver o mundo distante daquelas frases repetitivas e carregadas de pessimismo que permeiam o discurso do senso comum, como: O mundo é cruel! A vida é muito difícil! Viver é perigoso! Não confie nas pessoas!

A errância, desse ponto de vista, seria a expressão de uma outra relação com o outro e como mundo, menos ofensiva, mais carinhosa, um tanto lúdica, e seguramente trágica, repousando sobre a intuição da impermanência das coisas, dos seres e de seus relacionamentos. Sentimento trágico da vida que, desde então, se aplicará a gozar, no presente, o que é dado ver, o que é dado viver no cotidiano, e que achará seu sentido numa sucessão de instantes, preciosos por sua própria fugacidade. (MAFFESOLI, 2001, p. 28-29).

Viajar de moto faz parte dessa fugacidade, é uma ação que tenta quebrar, romper, esse pessimismo mundano. É feita por indivíduos que descobriram sentido nesse instante diferenciado, o de pilotar uma motocicleta e consegue, através dessa forma de deslocamento prazeroso, ver o mundo um tanto lúdico, como propõe Maffesoli (2001).

Contudo, o próprio autor chama atenção da dificuldade e das intempéries que irá passar quem se propor a viver esse nomadismo, o Estado Moderno não deseja os nômades, quer os fixos. "O nomadismo é totalmente antiético em relação à forma de Estado Moderno. E esta se preocupa constantemente em suprimir o que considera a sobrevivência de um modo de vida arcaico. Fixar significa a possibilidade de dominar." (MAFFESOLI, 2001, p.24). O que é móvel pode escapar facilmente e, para as gestões políticas de produtividade, é preciso desconfiar do que é errante, daquele que escapa aos olhos, que quer ser livre, mesmo por alguns momentos. 
Esse olhar negativo para o nômade, neste caso, o motociclista viajante, é fato constatado na mídia cinematográfica, no discurso e no olhar daquele que está de fora dos territórios por eles definidos. O motociclista ainda é visto como um fora da lei, um anti-social, um rebelde, vestido de couro, cheio de tatuagens e utilizando um veículo que facilita sua locomoção. "Eu acho esse povo muito feio e estranho, tenho até medo." (Entrevistado 04). “Todo ano esse povo de preto invade a Cidade de Goiás, mas ninguém da cidade vai nesse evento, é uma coisa só deles.” (Entrevistado 05).

Quando se ouve a voz "do de fora" é possível ouvir a voz da maioria, desses que não viajam de moto e não vão para os eventos motociclísticos, há nessa voz um sentimento de estranheza, que mesmo o motociclista estando em motocicletas de alto custo, ou seja, possui condições financeiras para ter adquirido aquele bem e sendo indivíduos com estabilidade profissional e familiar, vão ser julgados a partir de forças maiores que precisam denegrir esses indivíduos nômades. Desde os andarilhos, os moradores de rua, os hippies, poetas e jovens sem ponto de referência são considerados vagabundos nessa sociedade capitalista ocidental. Ao mesmo tempo são demonstrações de fragilidade desse estado que não prendem todos e que esse fechamento supostamente feito na modernidade, por todos os lados mostra sinal de fraqueza, os sujeitos dessa pesquisa são falhos no sistema de coibir o nomadismo do homem.

Outro fato é que o homem nômade, vagabundo aos olhos da maioria, é tido as vezes como um ser doente mental. Mafessoli (2001, p. 28) relembra que segundo o Budismo, utilizando a tradição zen da escola de Hui Neng "o não-pertencimento a um lugar é a própria condição de uma possível realização de si na plenitude do todo". Então, se o indivíduo não se sente pertencente a um lugar e precisa viajar para se encontrar, isso é a procura do seu eu, sendo assim, o termo vagabundo, insano mentalmente e não se encaixa nesses indivíduos.

\section{Mototurismo}

Dentro das modalidades turísticas existentes, preocupa-se neste artigo com o Mototurismo, o deslocar espacialmente utilizando a motocicleta, ora solitário ou em grupo, ora com sua própria motocicleta ou alugadas para esse fim. Um hobby que se tornou modalidade esportiva e que traz desde deslocamentos curtos até hallys e voltas ao mundo. Andar de motocicleta é hobby e viajar neste veículo é praticar mototurismo, assim definem-se os termos a partir desse momento utilizados.

No entanto, foi percebido que as viagens de motocicleta obedecem a um ponto final, a maioria dos praticantes de mototurismo viajam para Eventos Motociclísticos (Aniversários de Moto Clubes, Exposições de Motos Clássicas Antigas, Feiras de Motociclismo, Salões de Motocicletas, Encontros de Motociclistas, Festas para motociclistas, Lançamentos de Motocicletas, Inauguração de Revendedoras, Corridas, Hallys e Campeonatos de Moto Velocidade, Moto Cross, Motos de Trilhas e Apresentações de Manobras Radicais). Poucos e raros foram os motociclistas entrevistados que viajam para o lazer próprio, para uma cidade turística ou para um local que buscará desfrutar de 
um ponto turístico, eles viajam para encontrar os que praticam o mesmo hobby, como demonstra essa fala: "Quando viajo para outro lugar sem ser evento de moto, eu vou de carro e geralmente a família vai junto" (Entrevistado 06). Dessa maneira, os dois conceitos que permearão esse fragmento do artigo serão Mototurismo e Turismo de Eventos, esse último com foco nos eventos para os viajantes de motocicleta, os motociclistas.

Eventos estes que são divididos em duas categorias por Luz (2009), Eventos de Motoclubismo e Eventos Motociclísticos, o primeiro é vinculado aos Moto Clubes (eventos com menor número de pessoas, mais restrito, e geralmente em locais fechados) e o segundo engloba o motociclismo em geral, optam por espaços maiores e abertos (Centros de Convenções, Autódromos, Parques de Exposições e Praças Públicas) devido ao grande número de participantes. Esses eventos possuem uma finalidade específica, a de proporcionar momentos de prazer e descontração aos seus associados (no caso dos Moto Clubes) e divulgação do que há de novo nesse meio, vê-se nesse momento o caráter consumista.

O turismo é uma atividade importante para o desenvolvimento econômico, ambiental e social para diversos centros urbanos e zonas rurais, com relevantes números de crescimento no país e no mundo. Diferentes são as motivações que levam as pessoas se deslocarem para outras cidades, permanecerem naquele local por alguns dias e utilizarem das infraestruturas básicas e de turismo, como rede hoteleira, bares, restaurantes, entretenimentos e espaços de eventos. O turismo de evento se caracteriza pelo deslocamento de pessoas para participarem de evento que, em virtude de sua dinamicidade e interatividade com outros serviços da localidade onde é realizado este evento, traz reflexos em todos os níveis, econômicos, políticos, sociais, ambientais, culturais e físicos.

Os eventos são considerados como um produto turístico que, por si só, ampliam as taxas de permanência dos turistas no polo receptor, geram fluxos, atuam como atrativo turístico e permitem a diminuição da sazonalidade, resgatam e valorizam conteúdos culturais e naturais, dentre outros desdobramentos. Todos estes fatores favorecem a localidade, principalmente, quando ela não possui forte apelo motivacional e atratividade para a realização de outros tipos de turismo, como, por exemplo, o turismo de sol e praia, o ecoturismo, ou o turismo cultural.

Quando se utiliza ao termo "evento" trazem-se várias classificações, que podem ser quanto ao porte (pequeno, médio, grande) o que atualmente em virtude de sua amplitude, são classificados como megaeventos; à categoria, institucional ou promocional; e à área de interesse, (esportivo, técnico, científico, artístico, cultural, educativo, informativo, cívico, político, governamental, empresarial, religioso, folclórico, turístico, lazer, sócia).

Outra classificação é quanto ao tipo, que são diversos e a cada dia se criam novas tipologias, destacando-se: show, comício, simpósio, congresso e encontro. Este último é como o congresso em uma escala menor. Para a área de eventos técnicos e científicos, o congresso é considerado uma reunião entre profissionais de um segmento, geralmente organizado por uma entidade associativa, a fim de discutir e apresentar assuntos de interesse mútuo, com o intuito de atualização e/ou troca de saberes. O encontro, além 
de ser utilizado para dar o sentido de menor quantidade de participantes, ele pode ser dado a acontecimentos com o objetivo de reunir pessoas, com interesses comuns, com a finalidade de trocar experiências, assim como acontecem nos eventos motociclísticos, nomeados por encontros e organizados por associações ou clubes.

Para Meirelles (1999) o evento é um instrumento institucional promocional, com a finalidade de criar conceito e estabelecer a imagem de pessoas físicas, jurídicas, de produtos, serviços e ideias, por meio de um acontecimento previamente planejado, ao com um determinado espaço de tempo e com ênfase na aproximação entre os participantes, quer seja física, quer seja por meio de recursos da tecnologia. Essa aproximação dos participantes é o que mais impera nos eventos motociclísticos em geral, a partir dessa ação são definidos os próximos eventos, que são chamados por eles "apelidado" de encontros, e na linguagem de muitos motociclistas eles estão viajando para encontros, uns chamam de Encontros de Motos, outros de Encontros de Motociclistas. Encontrar os mesmos, os iguais, os de mesmo gosto, mesmo hobby.

Contudo, as indústrias de motocicletas e de acessórios para os motociclistas aproveitam esses eventos com outro fim, como propõe Canton (2002) ao ver o evento como um conjunto de atividades desenvolvidas com o objetivo de alcançar o seu públicoalvo através do lançamento de produtos, da apresentação de uma pessoa, empresa ou entidade, visando estabelecer o seu conceito ou recuperar sua imagem.

Para Zanella (2012) o evento é uma concentração ou reunião formal e solene de pessoas e/ou entidades realizada em data e local especial, como objetivo de celebrar acontecimentos importantes e significativos, assim como estabelecer contatos de natureza comercial, cultural, esportiva, social, familiar, religiosa e científica. Essa conceituação encaixa aos Eventos Motoclubistas, pois são nessas concentrações que ocorrem os batismos (entrada de um novo membro), reuniões anuais, e comemorações de seus aniversários de fundação. Ideia que confirma a argumentação do autor, vendo no evento um acontecimento especial, antecipadamente planejado e organizado, que reúne pessoas ligadas a interesses comuns, o viajar de motocicleta.

Na Cidade de Morrinhos - GO, que conta com 44.204 habitantes (IBGE, 2015), o Evento Motociclístico Parada Obrigatória está em sua $11^{\mathrm{a}}$ Edição, traz um público de 20.000 pessoas é visto pelo poder público como a grande atração turística da cidade. $\mathrm{O}$ evento era particular e foi tomado pelo poder público como um atrativo para vinda de turistas para a cidade, o que traz uma maior visibilidade à cidade e uma significativa entrada de capital.

Os eventos de motociclismo possuem uma repercussão maior entre seu público específico, que se programam para participarem destes encontros com antecedência e percorrem grandes distâncias para chegar ao destino final, o evento. Para a prática da atividade turística é preciso que as cidades possuam infraestrutura básica e de acesso. Um fator imprescindível para que a realização deste evento ocorra, é a boa condição das estradas. Afinal, é um evento que seus participantes não utilizam a malha aérea, mas sim, essencialmente, as estradas. Sendo assim, na fase de concepção do evento, o primeiro 
item que deve ser levado em consideração é o acesso rodoviário ao local do evento. Torna-se essencial enfatizar que as motocicletas possuem baixa autonomia (tanques de combustíveis pequenos) e necessitam de postos de combustíveis próximos, com distancias curtas, esse é um fato que explica as poucas viagens para o nordeste norte do Brasil, assim como a menor quantidade de Moto Clubes nessas regiões.

Os eventos de motociclismo são motivados pela integração daqueles que gostam de motocicletas, pelo exibicionismo, que é a possibilidade de "mostrar" aos outros a sua máquina ou a distância percorrida para estar naquele evento, pela compra e venda de produtos exclusivos e, principalmente, pela viagem em si, para "pegar a estrada" em suas motocicletas, ter o prazer e o sentimento de liberdade.

Na maioria dos eventos, a captação dos participantes deve iniciar-se no núcleo promotor, o local do evento, e a partir disso buscar formas crescentes e circulares de ampliação espacial para essa captação de público. Partindo com direção às regiões vizinhas, a fim de se fortalecer, e ampliar à medida que o evento se consolidou, adquirindo âmbitos: estadual, nacional e internacional. Entretanto, percebe-se que nos eventos de motociclismo essa difusão espacial não ocorre obedecendo a essa regra, o público vem de localidades distantes desde as primeiras edições, o caráter regional, nacional e global é dado pelo próprio público participante, daqueles que fazem mototurismo e são turistas quando estão no evento. O dito piegas "de boca em boca” é o grande divulgador desses tipos de eventos.

Embora o uso do termo mototurismo seja recente e são poucos os autores que tratam sobre o tema, há registros de viajantes sobre duas rodas desde o início do século XX. Unida à própria história do veículo, a motocicleta, que possui a primeira registrada na Alemanha em 1886, começou a ser utilizada para viagens longas e voltas ao mundo por aventureiros. Com a Primeira Guerra Mundial e em virtude do ambiente socioeconômico de pós-guerra (1914-1918), nos Estados Unidos e Inglaterra, as motocicletas se tornaram de baixo custo, manutenção fácil, sendo assim, acessível aos que possuíam menor poder aquisitivo (VIAGEM, 2014).

Nota-se que em suma, a maioria destas turnês (históricas e atuais) foi motivada pelo espírito de aventura e sentimento de liberdade e de descoberta que se pode desfrutar a partir de uma viagem de moto. São caracterizadas, principalmente, por percorrerem longos trechos em estradas, a fim de buscar por experiências diferenciadas das que teriam em atividades rotineiras ou em viagens tradicionais.

Atualmente existem empresas especializadas neste tipo de viagens espalhadas em todos os continentes, com seu público específico e cativo, que promovem viagens. Empresas de Mototurismo possibilitam você comprar somente o roteiro e viajar com a sua própria motocicleta ou, ainda, alugar com um "cardápio" bem variado, conforme a preferência de cada indivíduo. Estas viagens podem ser individuais ou em grupo, pode ser vendido um pacote com ou sem garupa e, até mesmo, em vans (veículos com capacidade para até 25 pessoas, que são suportes aos praticantes de mototurismo), muito 
utilizado para os que desejam acompanhar um grupo de motociclistas, mas não querem ou não podem montar em uma motocicleta.

Um pacote pode incluir: passagem aérea, locação da moto com capacetes e alforjes (malas laterais), seguro da moto e seguro da viagem, hospedagem, traslados, um líder do comboio das motos (como um guia, podendo ter um intérprete), equipe e veículo de apoio, com moto reserva, alimentação, combustível, mecânico, peças extras e GPSs. Um exemplo de uma demanda especial é o oferecido somente para mulheres motociclistas, para percorrer a ilustre Rota 66 nos Estados Unidos, organizado por uma agência de turismo brasileira (Figura 05).

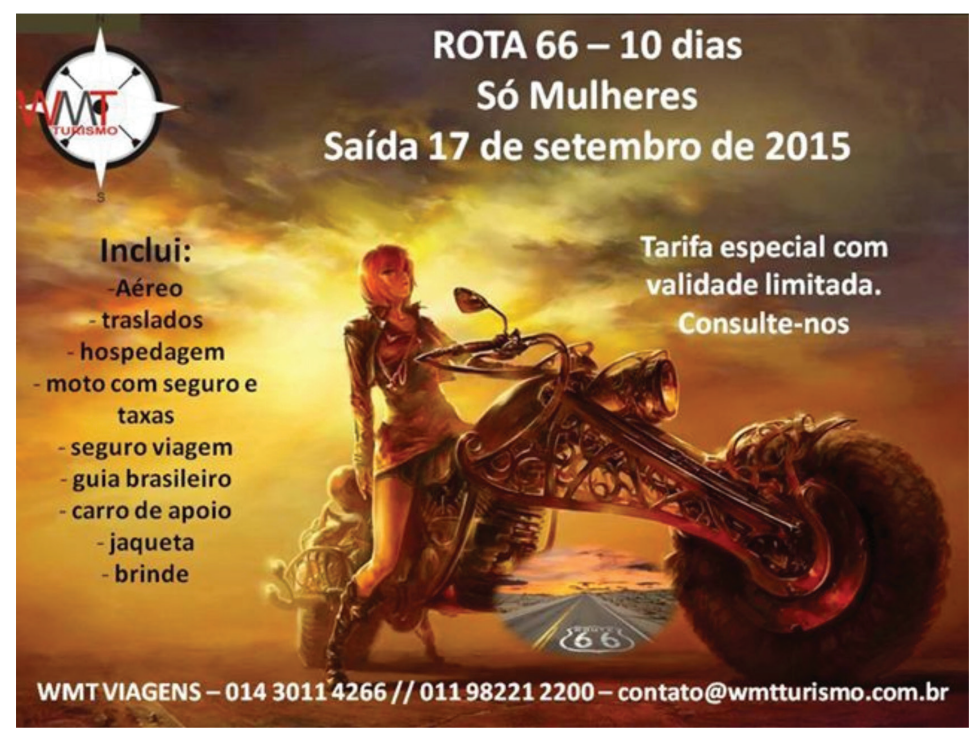

Figura 05: Pacote de Mototurismo

Fonte: WMT Turismo (2015)

Realizar uma viagem de motocicleta pode "caber em vários bolsos", tudo depende do perfil do viajante e do espírito aventureiro. Segundo a Agência WMT Turismo (2015) nos Estados Unidos é sugerido o aluguel de motos; em países europeus a conversão de moeda se torna algo complicado, sugerindo viajar por países que utilizam o euro; e na América Latina o mais acessível é viajar com sua própria motocicleta (se o piloto for brasileiro). Foi também citado por esta agência que o Evento Motociclístico mais procurado é o Daytona Beach Bike Week que acontece na Flórida-EUA, em sua 74 Edição, considerado o maior Evento Motociclístico do mundo (Figura 06). 


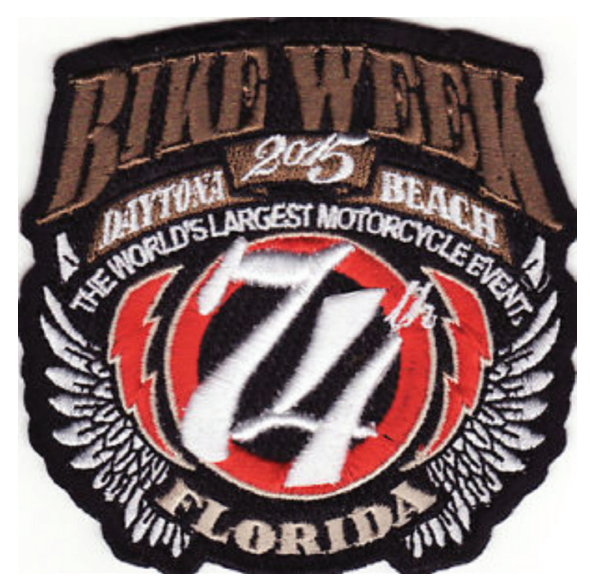

Figura 06: Daytona Beach Bike Week, 2015 Fonte: WMT Turismo (2015)

\section{Considerações Finais}

A liberdade é uma busca subjetiva do ser humano, encontrada nas mais diversas ações por eles desenvolvidas, contudo a liberdade discutida é a de viajar de motocicleta. A experiência de se sentir livre é uma sensação momentânea proporcionada por esse veículo nas estradas.

Toda ação, escolha e objetivo de vida passam a ser uma condição da própria existência humana e não uma conquista, partindo do pressuposto de que são produtos de uma liberdade. Ter uma moto para ter essa sensação de estar livre, é uma motivação pessoal, intrínseca em cada um e afirma a existência de uma liberdade temporária.

O motociclista faz como escolha o estilo de vida, abraçar sua paixão de viajar de moto, que, embora possam existir intempéries pelo caminho, ele tem o que busca: a liberdade, a qual, para eles, se torna experiências pessoais. O pilotar a moto na estrada e fazer parte daquela paisagem é mais importante do que a viagem em si. O importante é o percurso para se chegar no destino e não no fim dessa viagem.

Com este estilo de vida e público específico, cria-se mais um segmento no turismo, o mototurismo. Ele advém dessa motivação de sentir-se livre, mesmo que de forma momentânea. Entretanto, embora a sensação para o indivíduo seja temporária, o incremento social e econômico para as localidades por onde ele passa não é rompida, se reflete ainda por algum tempo. Por isso, muitos governantes viram no mototurismo um forte aliado ao turismo de eventos e, consequentemente, para o desenvolvimento das cidades, procurando garantir um calendário de eventos constante com a finalidade de manter contínua esta rede de geração de divisas.

O mototurismo é um movimento crescente em todo o país, com seus eventos fixos e móveis em diversas cidades. Somente o estado de Goiás conta com 32 encontros 
oficiais por ano. Entretanto, é um mercado que pode crescer ainda mais. Porém, para tal fato acontecer faz-se necessário que se tenha vontade empresarial e olhar político mais atencioso para as necessidades desta demanda e destes eventos. Assim, deixa-se propostas para futuras pesquisas o levantamento destes eventos no país e no mundo, o fomento que eles trazem para as localidades e as demandas exclusivas deste público.

\section{Agradecimentos}

À Coordenação de Aperfeiçoamento de Pessoal de Nível Superior (CAPES) pela concessão de Bolsa de Doutorado (2012-2015) à primeira autora; Bolsa de Doutorado (2014-2016) e de Doutorado Sanduíche no Exterior (2014-2015) à segunda autora; e Bolsa de Pós-Doutorado (20142015) ao terceiro autor.

\section{Referências}

BERGamini, C. W. Motivação: Mitos, Crenças e Mal-Entendidos. Revista de Administração de Empresas, São Paulo, n. 30 (2), jun. 1990. p. 23-34.

BRANDÃO, Felipe. 12 lindas estradas por onde você deve dirigir antes de morrer. Disponível em: <http://turismo.ig.com.br/destinos-internacionais/as-mais-incriveisestradas-do-mundo/n1597204838851.html>. Acesso em: 29 jan. 2015.

BRASIL caminhoneiro. Comportamento de motoristas de caminhão. Disponível em: <http://www.brasilcaminhoneiro.com.br/V4/comportamento/>. Acesso em: 29 jan. 2015.

BRASIL, Ministério do Turismo/ Fundação Getúlio Vargas. Sondagem do consumidor: intenção de viagem. Dez. 2014. Disponível em: <http://www.dadosefatos.turismo.gov. br/export/sites/default/dadosefatos/conjuntura_economica/sondagem_consumidor_ viagem/downloads_sondagem_consumidor/Sondagem_Dezembro_2014.pdf $>$. Acesso em: 20 jan. 2015.

CANTON, A.M. Eventos: ferramenta de sustentação para as organizações do terceiro setor. São Paulo: Rocca, 2002.

DIÁRIOS de motocicleta. Walter Salles, Film Four/BD Cine, Brasil, jan. 2004.

DIÁRIOS de um motociclista. Disponível em: <https://pt-br.facebook.com/.../Diáriosde-um-motociclista/348030011968>. Acesso em: 30 jun. 2014.

GRIMAL, P. Os erros da liberdade. Campinas: Papirus, 1990.

IBGE. Cidades: Goiás - Morrinhos. Disponível em: <http://www.cidades.ibge.gov.br/ xtras/perfil.php?lang=\&codmun $=521380 \&$ search $=$ goias $\mid$ morrinhos $>$. Acesso em: 29 jan . 2015.

LUZ, C. C. R. Sobre duas rodas: emoções e consumo no motociclismo. Dissertação de Mestrado em Ciências Sociais. Centro de Ciências Sociais, Instituto de Filosofia e Ciências Humanas, Universidade Estadual do Rio de Janeiro, Rio de Janeiro, 12 mai. 2009. 
MAFFESOLI, M. Saturação. Iluminuras: São Paulo, 1997.

MAFFESOLI, M. Sobre o Nomadismo: vagabundagens pós-modernas, Rio de Janeiro, Record, 2001.

MARTINS, Cleber. Psicanálise Clínica: Volição. Disponível em: $<$ http://psicanalisefocal. blogspot.com.br/2010/12/volicao.html>. Acesso em: 20 jun. 2014.

MEIRELLES, Gilda Fleury. Tudo sobre eventos. São Paulo: Editora STS, 1999.

MENDONÇA, E. P. A construção da liberdade. São Paulo: Convívio, 1977.

MINISTÉRIO DO TURISMO. Caracterização e dimensionamento do turismo doméstico no Brasil - 2010/2011. São Paulo: Fundação Instituto de Pesquisas Econômicas, set. 2012.

ONFRAY, M. Teoria da Viagem: Uma poética da Geografia. Lisboa: Quetzal textos breves, 2009.

SARTRE, J.P. O existencialismo é um humanismo. São Paulo: Nova Cultural, 1987.

SARTRE, J.P. O ser e o nada. Petrópolis: Vozes, 1999.

VIAGEM de moto. O que é mototurismo? Disponível em: $<$ http://www.viagemdemoto. com/index.php/historia/1080-a-historia-do-mototurismo>. Acesso em: 12 dez. 2014.

VIANA, N. S. O papel do indivíduo na história. Cadernos de História, Belo Horizonte, v. 14, n. 21, $2^{\circ}$ sem, 2013. p. 118-134.

WENGE, C. O. Razones para viajar. Factótum. Disponível em: <http://www. revistafactotum.com/revista/f_5/articulos/Factotum_5_8_Christian_Wenge.pdf $>$. Acesso em: 01 jul. 2014.

WMT TURISMO. Mototurismo. Disponível em: <https://www.facebook.com/pages/ WMT-Turismo-ME/801660569847121?sk=timeline\&ref=page_internal $>$. Acesso em: 29 jan. 2015.

ZANELLA, Luiz Carlos. Manual de Organização de eventos: planejamento e operacionalização. São Paulo: Editora Atlas, 2012.

RaQuel Lage Tuma

Bacharel em Turismo pela Universidade Católica Dom Bosco, Mestre em Turismo pelo Centro Universitário Ibero Americano e Doutora em Geografia pela Universidade Federal de Goiás, com doutorado sanduíche na Universidade de Paris IV-Sorbonne. Atualmente é professora substituta do Instituto Federal de Educação, Ciência e Tecnologia de Goiás.

Rua 75, no. 46. Centro. 74055-110 - Goiania, GO - Brasil.

E-mail: tuma.raquel@gmail.com 
Maria Elisabeth Alves Mesquita

Licenciada em Geografia pela Universidade Estadual de Goiás, Mestre e Doutora em Geografia pela Universidade Federal de Goiás. Atualmente é professora da Faculdade Alfredo Nasser e do Centro de Ensino de Tempo Integral Garavelo Park.

Av. Bela Vista, 26 - Jardim das Esmeraldas, Aparecida de Goiânia - GO E-mail: geoelisabeth@gmail.com

Carlos Eduardo Santos Maia

Graduado em Geografia pela Universidade do Estado do Rio de Janeiro, Mestre e Doutor em Geografia pela Universidade Federal do Rio de Janeiro e Pós-Doutor no ENEC, Universidade de Paris IV-Sorbonne. Atualmente é professor associado no Departamento de Geografia da Universidade Federal de Juiz de Fora.

UFJF, Instituto de Ciências Humanas. Rua José Lourenço Kelmer, s/n, Campus Universitário

São Pedro. 36036-330 - Juiz de Fora, MG - Brasil

E-mail: carlmaia@uol.com.br

Recebido para publicação em junho de 2015 Aprovado para publicação em outubro de 2015 